\title{
Do the Effects of ICT Use on Trip Generation Vary across Travel Modes? Evidence from Beijing
}

\author{
Chaoying Yin, ${ }^{1}$ Xiaoquan Wang, ${ }^{2}$ and Chunfu Shao $\mathbb{D}^{2}$ \\ ${ }^{1}$ College of Automobile and Traffic Engineering, Nanjing Forestry University, Nanjing, China \\ ${ }^{2}$ Key Laboratory of Transport Industry of Big Data Application Technologies for Comprehensive Transport, \\ Beijing Jiaotong University, Beijing 100044, China \\ Correspondence should be addressed to Chunfu Shao; cfshao2018@126.com
}

Received 10 November 2020; Revised 18 May 2021; Accepted 26 July 2021; Published 4 August 2021

Academic Editor: Michela Le Pira

Copyright (c) 2021 Chaoying Yin et al. This is an open access article distributed under the Creative Commons Attribution License, which permits unrestricted use, distribution, and reproduction in any medium, provided the original work is properly cited.

With the development of information and communication technologies (ICTs), considerable attention is being paid to the relationship between ICT use and travel behavior. However, it is unclear whether the effects of ICT use on trip generation vary across travel modes. Based on the data of 1022 respondents collected by a web-based questionnaire survey in Beijing, this study used a zero-inflated Poisson model to investigate the effects of ICT use on trip generation in different travel modes, in which ICT use was measured by both the time spent online and the Internet use frequency. The results indicated that the effects of ICT use on trip generation vary across auto, transit, and active trips. Moreover, two measurements of ICT use play essential roles in influencing a trip generation. Specifically, only the frequency of ordering food online showed a positive association with the likelihood of generating any transit trips. These findings demonstrate the importance of considering the differences across travel modes when analyzing the relationship between ICT use and trip generation.

\section{Introduction}

In the past few decades, information and communication technologies (ICTs) have attracted increasing attention. The smartphone is one of the most common ICT devices. The number of mobile Internet users was 817 million in China in 2018, accounting for $98.6 \%$ of all Internet users [1]. Smartphone use has influenced and changed various life domains, including shopping, making payments, and ordering food [2]. ICT use is reshaping people's daily lives, including how they live, work, and travel [3-6].

The existing research focuses on the relationship between ICT and travel behavior [7]. Additionally, several empirical studies have confirmed the role of ICT use in influencing travel behavior, although the results are mixed [8-12]. Several empirical studies used the time spent online as an indicator to investigate the relationship between ICT use and travel behavior $[8,13]$. For instance, Hong and Thakuriah found that the time spent online shows a positive association with a trip generation [8]. Apart from the time spent online, Internet use frequency is also a common indicator used in empirical studies. For instance, Delbosc and Mokhtarian [7] quantified the frequency of ICT use, including the phone, texting, e-mail, and social media, and explored the effects of ICT use frequency on social networking and physical travel. They found that four types of ICT use frequencies have a positive effect on trip generation. However, it is unclear whether and how the effects of the time spent online and the Internet use frequency on trip generation differ.

Whether the effects of ICT use on trip generation vary across different travel modes has been poorly examined, although the role of ICT use in influencing travel-related choices has been confirmed [10,14, 15]. Most existing studies focus on the effects of ICT use on total trip generation and pay limited attention to the trip generation in different travel modes. For instance, Wang and Law found that ICT use could positively influence the number of total daily trips [13]. Therefore, it is important to better understand the influence of ICT use on travel behavior by exploring the 
varying effects of ICT use on trip generation in different travel modes.

In this study, we identified two main research gaps in the literature. First, although previous research has focused on the relationship between ICT use and travel behavior, there is limited evidence on the different effects of the time spent online and the Internet use frequency [7]. Understanding these effects in a unified framework will help to make targeted policies to manage travel demand. Second, the literature provides limited evidence of the relationship between ICT use and travel behavior across different travel modes. ICT use may replace motorized trips by enabling people to participate in activities over the Internet. However, it is also possible that people with heavy ICT dependence have a preference for multitasking during public transit use $[16,17]$. Therefore, it is important to identify whether differences in the relationship between ICT use and trip generation across different travel modes exist.

To fill the aforementioned gaps, this study attempts to explore the effects of ICT use on trip generation in auto (i.e., private four-wheeler vehicles), public transit, and active modes (i.e., walking or cycling) based on a zero-inflated Poisson (ZIP) model. Based on survey data collected from Beijing in 2018, this study contributed to the literature by answering the following research questions: (1) Do the time spent online and Internet use frequency have different effects on trip generation? (2) Do the effects of ICT use on trip generation vary across travel modes?

The remainder of this paper is organized as follows. Section 2 reviews related studies. Section 3 describes the study regions, data, and modeling approach in this study. Section 4 presents the estimation results. In Section 5, the main findings and policy implications are discussed, which is followed by the conclusion in the final section.

\section{Literature Review and Theoretical Framework}

2.1. Literature Review. The relationship between ICT use and travel behavior has been explored from different perspectives $[18,19]$. Although researchers have provided extensive evidence of the influences of ICT use on travel behavior, the results are debatable [7, 20-22]. For example, teleworking can significantly reduce trips and distances traveled [23]. In addition, e-shopping has little substitution effect and may lead to more travel demand [24]. Based on a web-based survey, Tonn and Hemrick found that ICT use leads to both trip reduction and new trip generation, although weekly trips appear to be reduced by $8 \%$ [25]. Therefore, it is still debatable how ICT use influences travel behavior.

In the literature, ICT use is delineated with various measurements $[13,14,22,26]$. For instance, telecommuting is associated with travel mode choice [21], reduced vehicle miles traveled (VMT) [27], and increased social interaction [7]. Empirical studies show that e-shopping can replace some shopping trips but increases the shopping travel demand [24]. Farag et al. investigated how the frequencies of online searching, online buying, and in-store shopping trips relate to each other and found that online searching increases in-store shopping and e-shopping trips [9]. Social media use influences travel behavior and leads to a shift from auto to other modes. In recent years, smart technologies have attracted increasing attention and extensive studies have investigated the relationship between smartphone use and travel behavior [3, 28-30]. Zong and Zhang employed a random forest model to investigate the link between smartphone applications and life choices and found that smartphone applications can decrease daily trip generation [2]. Wang and Law used a structural equation model to explore the link between the time spent on ICT devices and travel behavior and found that ICT use positively influences trip generation [13]. ICT use frequency is also negatively associated with travel behavior [31]. However, it is still unclear whether the effects of the time spent online and Internet use frequency on trip generation differ.

The literature has also explored the relationship between ICT use and trip generation, considering various trip-related outcomes [28, 32-35]. Empirical studies confirm that ICT use not only has implications for travel demand but also influences activity participation, travel modes, routes, and departure time choices [36, 37]. Out-ofvehicle systems (e.g., mobile devices) and in-vehicle systems (e.g., advanced traveler information systems) may influence people's route choices and reduce travel time [38-41]. For example, advanced traveler information systems help travelers to access more information sources and adjust their travel decisions [42]. Based on repeated day-today revealed-preference observations, Tseng et al. found that the provision of traffic information indeed affects travel behavior [43]. The differences in trip planning between traditional online travelers and those who adopt alternative channels and products in search of deeper and more authentic experiences indicate that ICT use enables people to change their travel behavior [44]. ICT use can lead to a mode shift because it makes public transit and nonmotorized modes more attractive [22]. In terms of the effects of ICT use on auto dependence, applications for shared and public transport make auto ownership redundant [45]. In contrast, some applications can increase the auto demand because they can make driving more convenient [22]. In terms of the effects of ICT use on public transit, smartphone applications improve the quality of public transit by providing people with real-time operation information since transport reliability is usually believed to be an essential determinant of travel mode choice [46]. In terms of the effects on active modes, the development of bicycle rental platforms can significantly negatively influence auto dependence [47]. Existing ICT-related studies, however, pay limited attention to the varying effects of ICT use on trip generation in different travel modes.

2.2. Theoretical Framework. Two main research gaps based on the brief literature review motivated this study. First, few studies have explored the different effects of ICT use time and frequency on trip generation. Second, it is still unclear whether the effects of ICT use on trip generation vary across travel modes. Therefore, the objectives of this study were to 
examine the effects of the ICT use time and frequency and to determine how the effects vary across travel modes. To meet these objectives, a theoretical framework is proposed (Figure 1). On the one hand, we hypothesized that both the time spent online and the Internet use frequency were relevant to trip generation. In addition to ICT use, individual/household characteristics, built environment attributes, and the preferences for one specific travel mode are important factors influencing travel frequency $[3,48,49]$. Thus, these variables were controlled for in this study. On the other hand, we also hypothesized that the effects of ICT use on trip generation vary across travel modes. To support the above hypotheses, this study applied a ZIP model to investigate the varying effects of ICT use on trip generation in different travel modes based on web-surveyed data from Beijing, in which ICT use is delineated by two measurements, the time spent online and the Internet use frequency.

\section{Research Design}

3.1. Study Regions and Data. We choose Beijing, the capital of China, as the study region. Beijing is one of the biggest cities in China, with a population of 21.54 million as of 2018 and the political and cultural center of China. At the end of 2017, Beijing had 16 districts: 2 core functional districts, 4 urban function extended districts, 5 new urban development districts, and 5 ecological conservation districts (Figure 2). With rapid urbanization and informatization, the number of households having residential broadband access and mobile users reached 6.34 million and 40.09 million, respectively, in Beijing by the end of 2018. ICT development has had a dominant effect on daily life, which requires further examination of how Internet use interacts with travel behavior.

Data (individual travel behavior, built environment attributes, individual/household characteristics, and travel preferences) were obtained using a web-based questionnaire survey from September 2018 to February 2019 in Beijing. The survey was administered with the help of an Internet survey company. In total, 1037 respondents completed the survey. The sample covered 16 districts of Beijing, in which the distribution of the sampled population has corresponded with the whole population in Beijing. After removing records with missing data, the final sample comprised 1022 respondents. The questionnaire had five parts: (1) individual characteristics, (2) travel-related information about respondents, (3) built environment attributes near residential locations, (4) attitudes toward different travel modes, and (5) the use of smartphones and the Internet.

The questionnaire collected the respondents' auto trip, transit trip, and active trip frequencies of respondents for one week. Trip frequencies of three travel modes were used as dependent variables. Respondents were asked to report how many auto/transit/active trips they generated within one week, and 751 respondents generated car trips, 863 respondents generated transit trips, and 912 respondents generated active trips, respectively, within one week. The statistical descriptions of the variables used in this study are presented in Table 1.

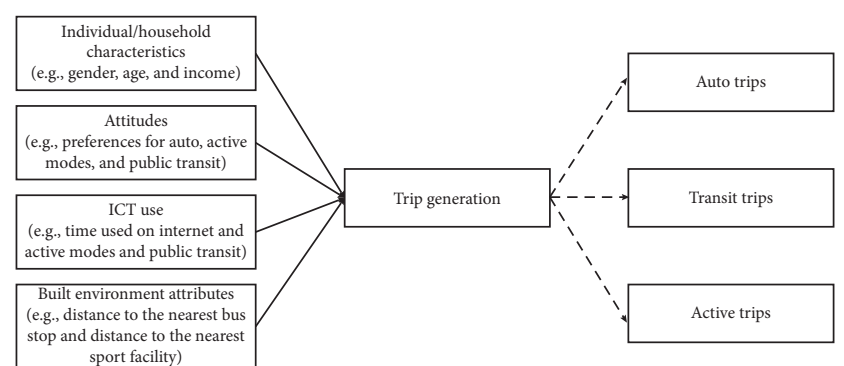

Figure 1: The theoretical framework of this study.

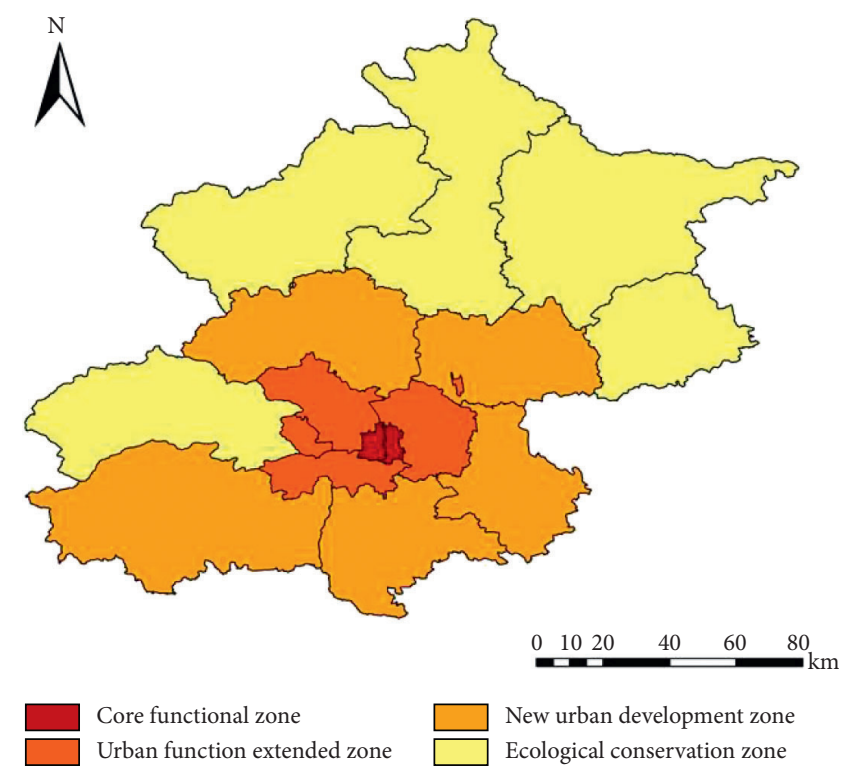

Figure 2: Location of the study area.

For the built environment attributes, the questions were divided into two parts. In the first part, the respondents reported where they lived. In the second part, they reported the distances from their residences to various facilities (i.e., the nearest bus stop, metro station, sports facility, garden, restaurant, and the mall) using a five-point scale from $1=$ distance below $300 \mathrm{~m}$ to $5=$ distance beyond $2000 \mathrm{~m}$. Data related to the residents' travel attitudes were collected by asking the respondents to report their preferences for three travel modes (i.e., auto, transit, and active) using a fivepoint scale from $1=$ strongly disagree to $5=$ strongly agree.

We also collected the residents' individual sociodemographic characteristics. The average age of the respondents was 34 years, and the average household size was 2.78 . $49.90 \%$ of the respondents were females, and $50.10 \%$ were males. In terms of education, $78.4 \%$ of the respondents have a college degree. Additionally, 9.24\% of the respondents had a monthly income of less than $3000 \mathrm{RMB}$ and $13.04 \%$ had a monthly income of more than $15000 \mathrm{RMB}$.

ICT devices are widely used by residents in daily life and influence their travel behavior. Three ICT-related variables were collected: time spent online, frequency of e-shopping, and frequency of ordering food online. The respondents reported their Internet use time on being asked the average time they spent online for nonwork purposes. The last two 
TABle 1: Variable definition and statistical description.

\begin{tabular}{|c|c|c|c|}
\hline Variable & Description & Case/mean & Percentage/S.E. \\
\hline \multicolumn{4}{|l|}{ Dependent variables } \\
\hline Any auto trips & $1=$ respondent generates auto trips; $0=$ otherwise & 751 & 73.48 \\
\hline Auto trips & The number of trips completed by car in the past week & 3.40 & 6.05 \\
\hline Any transit trips & $1=$ respondent generates transit trips; $0=$ otherwise & 863 & 84.44 \\
\hline Transit trips & The number of trips completed by the transit public in the past week & 5.40 & 16.49 \\
\hline Any active trips & $1=$ respondent generates active trips; $0=$ otherwise & 912 & 89.24 \\
\hline Active trips & The number of trips completed by walking/bicycling in the past week & 7.27 & 10.75 \\
\hline \multicolumn{4}{|l|}{ Built environment attributes } \\
\hline Core zone & $\begin{array}{l}1=\text { if the respondent lives within the core functional district; } \\
\qquad 0=\text { otherwise }\end{array}$ & 100 & 9.78 \\
\hline Extended zone & $\begin{array}{l}1=\text { if the respondent lives within the urban function extended district; } \\
\qquad 0=\text { otherwise }\end{array}$ & 449 & 43.93 \\
\hline Development zone & $\begin{array}{l}1=\text { if the respondent lives within the new urban development district; } \\
\qquad 0=\text { otherwise }\end{array}$ & 303 & 29.65 \\
\hline Ecological zone & $\begin{array}{l}1=\text { if the respondent lives within the ecological conservation district; } \\
0=\text { otherwise }\end{array}$ & 170 & 16.63 \\
\hline \multirow{5}{*}{ Distance to the nearest bus stop } & $1=$ distance below $300 \mathrm{~m}$ & 410 & 40.12 \\
\hline & $2=$ distance between 301 and $500 \mathrm{~m}$ & 273 & 26.71 \\
\hline & $3=$ distance between 501 and $1000 \mathrm{~m}$ & 253 & 24.76 \\
\hline & $4=$ distance between 1001 and $2000 \mathrm{~m}$ & 75 & 7.34 \\
\hline & $5=$ distance beyond $2000 \mathrm{~m}$ & 11 & 1.08 \\
\hline \multirow{5}{*}{$\begin{array}{l}\text { Distance to the nearest metro } \\
\text { station }\end{array}$} & $1=$ distance below $300 \mathrm{~m}$ & 76 & 7.44 \\
\hline & $2=$ distance between 301 and $500 \mathrm{~m}$ & 125 & 12.23 \\
\hline & $3=$ distance between 501 and $1000 \mathrm{~m}$ & 237 & 23.19 \\
\hline & $4=$ distance between 1001 and $2000 \mathrm{~m}$ & 248 & 24.27 \\
\hline & $5=$ distance beyond $2000 \mathrm{~m}$ & 336 & 32.88 \\
\hline \multirow{5}{*}{$\begin{array}{l}\text { Distance to the nearest sport } \\
\text { facility }\end{array}$} & $1=$ distance below $300 \mathrm{~m}$ & 340 & 33.27 \\
\hline & $2=$ distance between 301 and $500 \mathrm{~m}$ & 261 & 25.54 \\
\hline & $3=$ distance between 501 and $1000 \mathrm{~m}$ & 225 & 22.02 \\
\hline & $4=$ distance between 1001 and $2000 \mathrm{~m}$ & 107 & 10.47 \\
\hline & $5=$ distance beyond $2000 \mathrm{~m}$ & 89 & 8.71 \\
\hline \multirow{5}{*}{ Distance to the nearest garden } & $1=$ distance below $300 \mathrm{~m}$ & 158 & 15.46 \\
\hline & $2=$ distance between 301 and $500 \mathrm{~m}$ & 169 & 16.54 \\
\hline & $3=$ distance between 501 and $1000 \mathrm{~m}$ & 249 & 24.36 \\
\hline & $4=$ distance between 1001 and $2000 \mathrm{~m}$ & 212 & 20.74 \\
\hline & $5=$ distance beyond $2000 \mathrm{~m}$ & 234 & 22.90 \\
\hline \multirow{5}{*}{ Distance to the nearest restaurant } & $1=$ distance below $300 \mathrm{~m}$ & 482 & 47.16 \\
\hline & $2=$ distance between 301 and $500 \mathrm{~m}$ & 272 & 26.61 \\
\hline & $3=$ distance between 501 and $1000 \mathrm{~m}$ & 173 & 16.93 \\
\hline & $4=$ distance between 1001 and $2000 \mathrm{~m}$ & 68 & 6.65 \\
\hline & $5=$ distance beyond $2000 \mathrm{~m}$ & 27 & 2.64 \\
\hline \multirow{5}{*}{ Distance to the nearest mall } & $1=$ distance below $300 \mathrm{~m}$ & 61 & 5.97 \\
\hline & $2=$ distance between 301 and $500 \mathrm{~m}$ & 128 & 12.52 \\
\hline & $3=$ distance between 501 and $1000 \mathrm{~m}$ & 217 & 21.23 \\
\hline & $4=$ distance between 1001 and $2000 \mathrm{~m}$ & 278 & 27.20 \\
\hline & $5=$ distance beyond $2000 \mathrm{~m}$ & 338 & 33.07 \\
\hline \multicolumn{4}{|l|}{ Attitudes } \\
\hline \multirow{5}{*}{ Driving } & $1=$ strongly disagree & 28 & 2.74 \\
\hline & $2=$ disagree a little & 112 & 10.96 \\
\hline & $3=$ neither agree nor disagree & 475 & 46.48 \\
\hline & $4=$ agree a little & 282 & 27.59 \\
\hline & $5=$ strongly agree & 125 & 12.23 \\
\hline \multirow{5}{*}{ Public transport } & $1=$ strongly disagree & 13 & 1.27 \\
\hline & $2=$ disagree a little & 65 & 6.36 \\
\hline & $3=$ neither agree nor disagree & 295 & 28.86 \\
\hline & $4=$ agree a little & 397 & 38.85 \\
\hline & $5=$ strongly agree & 252 & 24.66 \\
\hline
\end{tabular}


TABLE 1: Continued.

\begin{tabular}{|c|c|c|c|}
\hline Variable & Description & Case/mean & Percentage/S.E. \\
\hline \multirow{5}{*}{ Walking } & $1=$ strongly disagree & 4 & 0.39 \\
\hline & $2=$ disagree a little & 38 & 3.72 \\
\hline & $3=$ neither agree nor disagree & 225 & 22.02 \\
\hline & $4=$ agree a little & 381 & 37.28 \\
\hline & $5=$ strongly agree & 374 & 36.59 \\
\hline \multicolumn{4}{|l|}{$\begin{array}{l}\text { Individual/household } \\
\text { characteristics }\end{array}$} \\
\hline Gender & $1=$ male $0=$ female & 50.10 & 0.50 \\
\hline \multirow[t]{4}{*}{ Age } & Age in years & 33.88 & 9.49 \\
\hline & $1=$ less than $3000 \mathrm{RMB} /$ month & 95 & 9.30 \\
\hline & $2=3001-4500 \mathrm{RMB} / \mathrm{month}$ & 103 & 10.08 \\
\hline & $3=4501-6000 \mathrm{RMB} /$ month & 145 & 14.19 \\
\hline \multirow[t]{4}{*}{ Income } & $4=6001-8000 \mathrm{RMB} /$ month & 186 & 18.20 \\
\hline & $5=8001-10000 \mathrm{RMB} /$ month & 175 & 17.12 \\
\hline & $6=10001-15000 \mathrm{RMB} / \mathrm{month}$ & 184 & 18.00 \\
\hline & $7=$ more than $15000 \mathrm{RMB} /$ month & 134 & 13.11 \\
\hline Education level & $1=$ having a college degree $0=$ having no college degree & 78.40 & 0.41 \\
\hline Household size & Number of persons in the household & 2.89 & 1.29 \\
\hline \multicolumn{4}{|l|}{ Internet use characteristics } \\
\hline \multirow[t]{3}{*}{ Time spent online } & Average time spent online for nonwork purposes & 4.01 & 2.92 \\
\hline & $1=$ never & 70 & 6.85 \\
\hline & $2=1-2$ times a month & 234 & 22.90 \\
\hline \multirow[t]{4}{*}{ Frequency of e-shopping } & $3=1-2$ times a week & 380 & 37.18 \\
\hline & $4=2-3$ times a week & 229 & 22.41 \\
\hline & $5=$ every day & 109 & 10.67 \\
\hline & $1=$ never & 270 & 26.42 \\
\hline \multirow{4}{*}{$\begin{array}{l}\text { Frequency of ordering food } \\
\text { online }\end{array}$} & $2=1-2$ times a month & 202 & 19.77 \\
\hline & $3=1-2$ times a week & 262 & 25.64 \\
\hline & $4=2-3$ times a week & 196 & 19.18 \\
\hline & $5=$ everyday & 92 & 9.00 \\
\hline
\end{tabular}

variables were collected by asking the respondents to report their frequency of e-shopping and ordering food online using a five-point scale from $1=$ never to $5=$ every day. The average time spent online for nonwork purposes was $4.01 \mathrm{~h} /$ day. The respondents were also asked to report the frequencies of online shopping and ordering take-out food (never, 1-2 times a month, 1-2 times a week, 2-3 times a week, or every day). Pearson correlation coefficients between the three variables were calculated (see Table 2). No multicollinearity exists among the three variables because correlations are smaller than 0.8 [50]. Moreover, the correlation coefficients indicate that it is necessary to consider the effects of both the time spent online and the Internet use frequency.

3.2. Modeling Approach. To examine the relationship between ICT use and trip generation, a ZIP model was used in this study. The dependent variables were of two types: binary (whether respondents generate any auto/transit/active trips) and count (the number of auto/transit/active trips the respondents generate). The ZIP model is a typical count data modeling approach that is appropriate for modeling trip frequencies because it shows the characteristics of a discrete distribution that is nonnegative and has integer values [51]. Among various count data modeling approaches, the Poisson model is widely used for trip generation modeling because trips occur randomly and independently [52]. In the case of specific-mode trips, there exist zero and non-zero values among the observations. However, a Poisson model cannot address the excess zeros in the data, while a ZIP model explicitly separates the true zero-state and the count data processes. Therefore, we used a ZIP model for empirical analysis. The mathematical formulas of a ZIP model are described below.

Assuming that $Y_{i}$ denotes the auto/transit/active trips generated by the $i$ - th observation, a ZIP model is represented as follows:

$$
\operatorname{Pr}\left(Y_{i}=y_{i}\right)= \begin{cases}\pi_{i}+\left(1-\pi_{i}\right) \exp \left(-\lambda_{i}\right), & \text { if } y_{i}=0 \\ \left(1-\pi_{i}\right) \frac{\exp \left(-\lambda_{i}\right) \lambda_{i}^{y_{i}}}{y_{i} !}, & \text { if } y_{i}>0\end{cases}
$$

where $\pi_{i}$ is the probability of an excess zero and $\lambda_{i}$ is the parameter to be estimated.

The mean and variance of $Y_{i}$ in the ZIP model are as follows, respectively:

$$
\begin{aligned}
E\left(Y_{i}\right) & =\left(1-\pi_{i}\right) \lambda_{i}, \\
\operatorname{Var}\left(Y_{i}\right) & =\left(1-\pi_{i}\right) \lambda_{i}\left(1+\pi_{i} \lambda\right) .
\end{aligned}
$$

In the ZIP model, $\pi_{i}$ is usually modeled with a binary logit regression model. In this study, a logit model was used to regress Internet use characteristics, built environment 
TABLE 2: Correlation coefficients between ICT variables.

\begin{tabular}{lccc}
\hline Variables & Time spent online & Frequency of e-shopping & Frequency of ordering food online \\
\hline Time spent online & - & - & - \\
Frequency of e-shopping & 0.08 & - & - \\
Frequency of ordering food online & 0.07 & 0.31 & - \\
\hline
\end{tabular}

attributes, and individual characteristics on auto, active, and transit trip frequencies, respectively, as follows:

$$
\begin{aligned}
\operatorname{logit}\left(\pi_{i}\right)= & \alpha+\beta_{\mathrm{BE}}^{T} x_{\mathrm{BE} i}+\beta_{\mathrm{SE}}^{T} x_{\mathrm{SE} i}+\beta_{\mathrm{LC}}^{T} x_{\mathrm{LC} i} \\
& +\beta_{\mathrm{ICT}}^{T} x_{\mathrm{ICT} i}+\zeta_{i},
\end{aligned}
$$

where $x_{\mathrm{BE} i}, x_{\mathrm{SE} i}, x_{\mathrm{LC} i}$ and $x_{\mathrm{ICT} i}$ are the built environment, individual, location, and Internet use characteristics, respectively, and $\beta_{\mathrm{BE}}, \beta_{\mathrm{SE}}, \beta_{\mathrm{LC}}$, and $\beta_{\mathrm{ICT}}$ are the corresponding parameters. $\alpha$ is the fixed intercept and $\zeta_{i}$ is an error term following a Gumbel distribution.

\section{Model Results}

To explore the effects of ICT use on trip generation, three ZIP models for different travel modes (i.e., auto, active, and public transit) were separately estimated in this study. As the analysis was conducted based on cross-sectional survey data, all effects on trip generation are only associations between variables, not causal relationships.

4.1. Effects on Auto Trips. The estimation results of the ZIP model for auto trips and the number of auto trips (Table 3 ) show that Internet use characteristics are important factors of auto trip generation. The likelihood of generating any auto trips decreases with the time spent online. The number of auto trips is not significantly associated with the time spent online but with the frequency of e-shopping and the frequency of ordering food online. Specifically, people who have a higher frequency of e-shopping and ordering food online are less likely to have more auto trips. These negative effects are consistent with most existing studies, which confirm that ICT use may deter motorized trips [48].

Regarding built environment attributes, compared with those living in the ecological zone, people living in the core, extended, and development zones could have a lower likelihood of generating auto trips. This may be due to the fact that most employment opportunities and facilities are concentrated around the city center [53]. Thus, people living in the ecological zone tend to use cars because they usually take longer trips. The distance to the nearest metro station has a significantly positive effect on the likelihood of generating auto trips. Regarding public facilities, there is a positive correlation between the distance to the nearest sports facilities and auto trip generation. Only the distance to the nearest sports facilities and the distance to the nearest garden are significantly related to auto trips $(90 \%$ significance level), indicating that people living further away from public facilities tend to generate more auto trips.

All variables of travel attitudes significantly influence the likelihood of generating auto trips, while only the preference for public transit significantly influences the number of auto trips. There is a positive correlation between the people who prefer to drive and the likelihood of generating auto trips. As expected, the preference for public transit and active modes could reduce the likelihood of generating auto trips. Unexpectedly, the preference for public transit increases the number of auto trips. This may be due to the fact that when transit accessibility is poor, transit trips could be replaced by car trips because people usually choose these modes when making long-distance trips.

Regarding individual characteristics, all variables significantly influence the likelihood of generating auto trips. Specifically, older people and males who have higher incomes tend to have a higher likelihood of generating auto trips. The education shows a significant negative association with the likelihood of generating auto trips. Likewise, the negative effect of the education level on the number of auto trips is significant ( $90 \%$ significance level). In addition, household size is positively related to the likelihood of generating auto trips, whereas the relationship between household size and the number of auto trips is significantly negative.

4.2. Effects on Public Transit Trips. Table 4 shows the estimation results of public transit trip generation. Regarding Internet use characteristics, only the frequency of ordering food online shows a positive effect on the likelihood of generating transit trips.

Regarding built environment attributes, people living in the core zone may have a higher likelihood of generating transit trips compared with those living in the ecological zone. Additionally, people living in the core, extend, and development zones tend to generate fewer transit trips. Longer distances to the nearest metro station, restaurant, and mall could reduce the likelihood of generating transit trips. Conversely, distances to the nearest sports facilities and garden positively influence the likelihood of generating transit trips.

Regarding travel attitudes, people preferring public transit may have a higher likelihood of generating transit trips. In contrast, people preferring driving and active modes may have a lower likelihood of generating transit trips. People preferring public transit are more likely to generate more transit trips.

Regarding the socioeconomic levels, men from households with higher incomes have a higher likelihood of generating transit trips. Older people with a higher education level and from bigger households have a lower likelihood of generating transit trips. Among all socioeconomic levels, only age is positively associated with the number of transit trips. 
TABLE 3: Estimated effects of ICT use on auto trips.

\begin{tabular}{|c|c|c|c|c|}
\hline \multirow{2}{*}{ Variable } & \multicolumn{2}{|c|}{ Any auto trips } & \multicolumn{2}{|c|}{ Number of auto trips } \\
\hline & Coefficient & S.E. & Coefficient & S.E. \\
\hline \multicolumn{5}{|l|}{ Internet use characteristics } \\
\hline Time spent online & $-0.021^{* * *}$ & 0.006 & -0.015 & 0.031 \\
\hline Frequency of e-shopping & 0.019 & 0.017 & $-0.206^{* *}$ & 0.093 \\
\hline Frequency of ordering food online & 0.000 & 0.016 & $-0.1986^{* *}$ & 0.083 \\
\hline \multicolumn{5}{|l|}{$\begin{array}{l}\text { Built environment attributes } \\
\text { (Reference: ecological zone) }\end{array}$} \\
\hline Core zone & $-0.302^{* * *}$ & 0.074 & 0.247 & 0.392 \\
\hline Extended zone & $-0.409^{* * *}$ & 0.050 & 0.001 & 0.279 \\
\hline Development zone & $-0.348^{* * *}$ & 0.050 & -0.186 & 0.280 \\
\hline Distance to the nearest bus stop & -0.020 & 0.019 & -0.095 & 0.102 \\
\hline Distance to the nearest metro station & $0.087^{* * *}$ & 0.017 & -0.034 & 0.085 \\
\hline Distance to the nearest sport facilities & $0.053^{* * *}$ & 0.015 & $0.124^{*}$ & 0.073 \\
\hline Distance to the nearest garden & -0.0023 & 0.014 & $0.144^{*}$ & 0.075 \\
\hline Distance to the nearest restaurant & 0.010 & 0.019 & -0.144 & 0.098 \\
\hline Distance to the nearest mall & -0.0013 & 0.016 & -0.034 & 0.079 \\
\hline \multicolumn{5}{|l|}{ Attitudes } \\
\hline Driving & $0.233^{* * *}$ & 0.021 & -0.404 & 0.004 \\
\hline Public transit & $-0.201^{* * *}$ & 0.020 & $0.348^{* * *}$ & 0.115 \\
\hline Walking & $-0.087^{* * *}$ & 0.022 & 0.026 & 0.121 \\
\hline \multicolumn{5}{|l|}{ Individual/household characteristics } \\
\hline Gender & $0.123^{* * *}$ & 0.037 & 0.191 & 0.194 \\
\hline Age & $0.007^{* * *}$ & 0.002 & 0.039 & 0.035 \\
\hline Income & $0.039^{* * *}$ & 0.012 & 0.217 & 0.135 \\
\hline Education level & $-0.254^{* * *}$ & 0.047 & $-0.440^{*}$ & 0.226 \\
\hline Household size & $0.042^{* * *}$ & 0.014 & $-0.422^{* * *}$ & 0.082 \\
\hline Pseudo- $R^{2}$ & 0.59 & & 0.22 & \\
\hline
\end{tabular}

Note: * Significance level of $10 \% .{ }^{* *}$ Significance level of $5 \% .{ }^{* * *}$ Significance level of $1 \%$.

4.3. Effects on Active Trips. Table 5 shows the estimation results for an active trip generation. ICT use plays an essential role in influencing an active trip generation. The time spent online positively influences two outcomes. People spending more time on Internet devices may have a higher likelihood of generating active trips and tend to have more active trips. This result supports Hong and Thakuriah's study [3], which found that smartphone use plays an important role in increasing active trips. Conversely, the frequency of e-shopping and ordering food online negatively influence the likelihood of generating active trips.

Built environment attributes significantly influence the likelihood of generating active trips but not the number of active trips. Specifically, people living in the core, extended, and development zones may have a higher probability of generating active trips compared with those living in the ecological zone. Distances to the nearest bus stop and sports facility positively influence the likelihood of generating active trips. Additionally, the distance to the nearest garden negatively influences the likelihood of generating active trips.

Regarding travel attitudes, people who like driving may have a lower likelihood of generating active trips and tend to have fewer active trips. People who prefer public transit could have a higher likelihood of generating active trips. As expected, people preferring active modes may have a higher likelihood of generating active trips and tend to have more active trips.
Regarding the effects of the socioeconomic levels, only income and household size show a positive correlation with the likelihood of generating active trips. The results show that older people tend to generate more active trips.

\section{Discussion and Policy Implications}

5.1. Discussion. Using survey data from Beijing, this study investigated the effects of ICT use on trip generation in different travel modes by applying a ZIP model. The results contribute to the literature by (1) revealing the different effects of both the time spent online and the Internet use frequency on trip generation; (2) exploring whether the effects of ICT use on trip generation vary across different travel modes.

First, the time spent online plays an important role in a trip generation. Specifically, it reduces the likelihood of generating auto trips. This finding can be explained by the fact that people could replace some trips with a "virtual" interaction with friends [7]. The time spent online positively influences the number of active trips. These results indicate that people with heavy ICT dependence may be more likely to generate active trips.

Second, the Internet use frequency also influences a trip generation. Specifically, people who have a higher frequency of e-shopping and ordering food online tend to generate fewer auto trips. Meanwhile, a higher frequency of e-shopping and ordering food online could also reduce the 
TABLE 4: Estimated effects of ICT use on transit trips.

\begin{tabular}{|c|c|c|c|c|}
\hline \multirow{2}{*}{ Variable } & \multicolumn{2}{|c|}{ Any transit trips } & \multicolumn{2}{|c|}{ Transit trips } \\
\hline & Coefficient & S.E. & Coefficient & S.E. \\
\hline \multicolumn{5}{|l|}{ Internet use characteristics } \\
\hline Time spent online & 0.004 & 0.005 & -0.038 & 0.040 \\
\hline Frequency of e-shopping & 0.016 & 0.014 & 0.084 & 0.100 \\
\hline Frequency of ordering food online & $0.082^{* * *}$ & 0.011 & 0.034 & 0.088 \\
\hline \multicolumn{5}{|l|}{$\begin{array}{l}\text { Built environment attributes } \\
\text { (Reference: ecological zone) }\end{array}$} \\
\hline Core zone & $-0.262^{* * *}$ & 0.065 & $-1.118^{* * *}$ & 0.413 \\
\hline Extended zone & 0.077 & 0.047 & $-1.387^{* * *}$ & 0.282 \\
\hline Development zone & 0.001 & 0.049 & $-1.087^{* * *}$ & 0.279 \\
\hline Distance to the nearest bus stop & -0.012 & 0.015 & -0.066 & 0.113 \\
\hline Distance to the nearest metro station & $-0.091^{* * *}$ & 0.012 & 0.026 & 0.092 \\
\hline Distance to the nearest sport facilities & $0.155^{* * *}$ & 0.011 & -0.031 & 0.083 \\
\hline Distance to the nearest garden & $0.040^{* * *}$ & 0.011 & 0.053 & 0.081 \\
\hline Distance to the nearest restaurant & $-0.024^{*}$ & 0.014 & -0.008 & 0.109 \\
\hline Distance to the nearest mall & $-0.025^{* *}$ & 0.012 & -0.131 & 0.087 \\
\hline \multicolumn{5}{|l|}{ Attitudes } \\
\hline Driving & $-0.094^{* * *}$ & 0.015 & 0.055 & 0.114 \\
\hline Public transit & $0.340^{* * *}$ & 0.018 & $0.663^{* * *}$ & 0.117 \\
\hline Walking & $-0.146^{* * *}$ & 0.018 & 0.168 & 0.129 \\
\hline \multicolumn{5}{|l|}{ Individual/household characteristics } \\
\hline Gender & $0.155^{* * *}$ & 0.029 & -0.002 & 0.208 \\
\hline Age & $-0.007^{* * *}$ & 0.001 & $0.020^{*}$ & 0.011 \\
\hline Income & $0.069^{* * *}$ & 0.008 & 0.013 & 0.064 \\
\hline Education level & $-0.076^{*}$ & 0.038 & -0.393 & 0.250 \\
\hline Household size & $-0.028^{*}$ & 0.011 & 0.075 & 0.078 \\
\hline Pseudo- $R^{2}$ & 0.48 & & 0.20 & \\
\hline
\end{tabular}

Note: * Significance level of $10 \% .{ }^{* *}$ Significance level of $5 \% .{ }^{* * *}$ Significance level of $1 \%$.

TABle 5: Estimated effects of ICT use on active trips.

\begin{tabular}{|c|c|c|c|c|}
\hline \multirow{2}{*}{ Variable } & \multicolumn{2}{|c|}{ Any active trips } & \multicolumn{2}{|c|}{ Active trips } \\
\hline & Coef. & S.E. & Coef. & S.E. \\
\hline \multicolumn{5}{|l|}{ Internet use characteristics } \\
\hline Time spent online & $0.008^{*}$ & 0.004 & $0.066^{* *}$ & 0.029 \\
\hline Frequency of e-shopping & $-0.084^{* * *}$ & 0.012 & -0.118 & 0.107 \\
\hline Frequency of ordering food online & $-0.055^{* * *}$ & 0.010 & 0.067 & 0.094 \\
\hline \multicolumn{5}{|l|}{$\begin{array}{l}\text { Built environment attributes } \\
\text { (reference: ecological zone) }\end{array}$} \\
\hline Core zone & $0.137^{* * *}$ & 0.052 & -0.323 & 0.444 \\
\hline Extended zone & $0.126^{* * *}$ & 0.038 & -0.438 & 0.308 \\
\hline Development zone & $0.211^{* * *}$ & 0.037 & -0.264 & 0.309 \\
\hline Distance to the nearest bus stop & $0.053^{* * *}$ & 0.012 & -0.151 & 0.118 \\
\hline Distance to the nearest metro station & 0.013 & 0.011 & 0.067 & 0.099 \\
\hline Distance to the nearest sport facilities & $0.069^{* * *}$ & 0.009 & -0.031 & 0.087 \\
\hline Distance to the nearest garden & $-0.106^{* * *}$ & 0.009 & -0.007 & 0.086 \\
\hline Distance to the nearest restaurant & 0.019 & 0.012 & 0.118 & 0.108 \\
\hline Distance to the nearest mall & -0.009 & 0.010 & 0.144 & 0.100 \\
\hline \multicolumn{5}{|l|}{ Attitudes } \\
\hline Driving & $-0.160^{* * *}$ & 0.013 & $-0.365^{* * *}$ & 0.126 \\
\hline Public transit & $0.086^{* * *}$ & 0.014 & -0.169 & 0.124 \\
\hline Walking & $0.080^{* * *}$ & 0.016 & $0.325^{* *}$ & 0.132 \\
\hline \multicolumn{5}{|l|}{ Individual/household characteristics } \\
\hline Gender & 0.002 & 0.024 & -0.052 & 0.223 \\
\hline Age & -0.001 & 0.001 & $0.040^{* * *}$ & 0.012 \\
\hline Income & $-0.041^{* * *}$ & 0.007 & 0.048 & 0.068 \\
\hline Education level & 0.027 & 0.030 & 0.028 & 0.277 \\
\hline Household size & $-0.071^{* * *}$ & 0.009 & -0.114 & 0.087 \\
\hline Pseudo- $R^{2}$ & 0.67 & & 0.28 & \\
\hline
\end{tabular}

Note: ${ }^{*}$ Significance level of $10 \% .{ }^{* *}$ Significance level of $5 \% .{ }^{* * *}$ Significance level of $1 \%$. 
likelihood of generating active trips. Unexpectedly, people who have a higher frequency of ordering food online are more likely to generate public transit trips. This may be partially explained by the fact that public transit use makes multitasking convenient [17].

Third, the effects of ICT use vary across different travel modes. ICT use has more effect on active trip generation. Specifically, the time spent online is related to the likelihood of generating auto and active trips. In contrast, the frequency of e-shopping reduces the likelihood of generating active trips. The frequency of ordering food online also reduces the likelihood of generating active trips but increases the likelihood of generating public transit trips. Both frequencies of ordering food online and e-shopping reduces the number of auto trips.

5.2. Policy Implications. Although this study only captured associations between ICT use and trip generation, the findings can inform some policy responses. Encouraging ICT use may lead to a more environmentally friendly society. The estimation results show that ICT use negatively influences auto trip generation, although its effects on active trip generation are complex. The negative effects on auto trip generation may be explained by the fact that traveling by car does not allow multitasking. Thus, people who prefer using ICTs during trips may go on fewer auto trips. The positive effects of public transit partially support this explanation. These findings imply that ICT use could improve the quality of life but may also aggravate environmental problems. Second, the estimation results suggest that ICT use frequency may increase public transit use. This may be partially explained by the fact that multitasking is convenient during public transit use. This finding may provide a reference for the implementation of automatic driving technology because one important characteristic of automatic driving technology is to allow multitasking.

\section{Conclusion}

Based on a sample of 1022 individuals from Beijing, this paper used a ZIP model to explore the effects of ICT use on trip generation across different travel modes. Specifically, the results show that the time spent online is negatively correlated with the likelihood of generating auto trips, while the Internet use frequency (i.e., e-shopping and ordering food online) is associated with the number of auto trips. The frequency of ordering food online is positively correlated with the likelihood of generating transit trips. Additionally, the time spent online is positively associated with the likelihood of generating active trips, but the Internet use frequency (i.e., e-shopping and ordering food online) negatively influences the likelihood of generating active trips. Only the time spent online is positively associated with the number of active trips, indicating that more time spent online can increase active trips.

This study had a few limitations. First, the analysis was based on cross-sectional data collected within a single year. Therefore, the estimation results did not show the causality between ICT use and trip generation. In future work, to analyze causality, a panel survey should be performed to determine the changes in trip generation caused by ICT use. Second, only data from one city were used for analysis. Travel behavior is context-related, so data from more cities and countries are needed for future analysis to obtain extensible insight into the relationship between ICT use and travel behavior.

\section{Data Availability}

The authors have no right to share the data because they belong to the research group not only the authors.

\section{Conflicts of Interest}

The authors declare that they have no conflicts of interest.

\section{Acknowledgments}

This work was sponsored by the National Natural Science Foundation of China (No. 71621001 and No. 52072025).

\section{References}

[1] P. Nie, W. Ma, and A. Sousa-Poza, "The relationship between smartphone use and subjective well-being in rural China," Electronic Commerce Research, pp. 1-27, 2020.

[2] W. Zong and J. Zhang, "Use of smartphone applications and its impacts on urban life: a survey and random forest analysis in Japan," Sustainable Cities and Society, vol. 49, Article ID 101589, 2019.

[3] J. Hong and P. V. Thakuriah, "Examining the relationship between different urbanization settings, smartphone use to access the internet and trip frequencies," Journal of Transport Geography, vol. 69, pp. 11-18, 2018.

[4] Y. Zhou and X. Wang, "Explore the relationship between online shopping and shopping trips: an analysis with the 2009 NHTS data," Transportation Research Part A: Policy and Practice, vol. 70, pp. 1-9, 2014.

[5] S. Fang and J. Ma, "Experimental analysis of driver visual characteristics in urban tunnels," Applied Sciences, vol. 2021, p. 14, 2021.

[6] G. Li, J. Ma, and Q. Shen, "Modeling of merging decision during execution period based on random forest," Journal of Advanced Transportation, vol. 2021, Article ID 6654096, 11 pages, 2021.

[7] A. Delbosc and P. Mokhtarian, "Face to facebook: the relationship between social media and social travel," Transport Policy, vol. 68, pp. 20-27, 2018.

[8] J. Hong and P. Thakuriah, "Relationship between motorized travel and time spent online for nonwork purposes: an examination of location impact," International Journal of Sustainable Transportation, vol. 10, no. 7, pp. 617-626, 2016.

[9] S. Farag, T. Schwanen, M. Dijst, and J. Faber, "Shopping online and/or in-store? a structural equation model of the relationships between e-shopping and in-store shopping," Transportation Research Part A: Policy and Practice, vol. 41, no. 2, pp. 125-141, 2007.

[10] P. Mokhtarian, "If telecommunication is such a good substitute for travel, why does congestion continue to get worse?" Transportation Letters, vol. 1, no. 1, pp. 1-17, 2009. 
[11] S. Choo, T. Lee, and P. L. Mokhtarian, "Do transportation and communications tend to be substitutes, complements, or neither?" Transportation Research Record: Journal of the Transportation Research Board, vol. 2010, no. 1, pp. 121-132, 2007.

[12] U. Lachapelle and F. Jean-Germain, "Personal use of the internet and travel: evidence from the Canadian general social survey's 2010 time use module," Travel Behaviour and Society, vol. 14, pp. 81-91, 2019.

[13] D. Wang and F. Y. T. Law, "Impacts of information and communication technologies (ICT) on time use and travel behavior: a structural equations analysis," Transportation, vol. 34 , no. 4 , pp. 513-527, 2007.

[14] P. L. Mokhtarian, I. Salomon, and S. L. Handy, "The impacts of ICT on leisure activities and travel: a conceptual exploration," Transportation, vol. 33, no. 3, pp. 263-289, 2006.

[15] Y. Yuan, M. Raubal, and Y. Liu, "Correlating mobile phone usage and travel behavior-a case study of Harbin, China," Computers, Environment and Urban Systems, vol. 36, no. 2, pp. 118-130, 2012.

[16] X.M. Fu, "Does heavy ICT usage contribute to the adoption of ride-hailing app?" Travel Behaviour and Society, vol. 21, pp. 101-108, 2020.

[17] R. Krueger, T. H. Rashidi, and J. Auld, "Preferences for travelbased multitasking: evidence from a survey among public transit users in the Chicago metropolitan area," Transportation Research Part F: Traffic Psychology and Behaviour, vol. 65, pp. 334-343, 2019.

[18] P. Andreev, I. Salomon, and N. Pliskin, "Review: state of teleactivities," Transportation Research Part C: Emerging Technologies, vol. 18, no. 1, pp. 3-20, 2010.

[19] O. Rotem-Mindali and J. W. J. Weltevreden, "Transport effects of e-commerce: what can be learned after years of research?” Transportation, vol. 40, no. 5, pp. 867-885, 2013.

[20] S. Kenyon, "The impacts of Internet use upon activity participation and travel: results from a longitudinal diary-based panel study," Transportation Research Part C: Emerging Technologies, vol. 18, no. 1, pp. 21-35, 2010.

[21] R. M. Pendyala, K. G. Goulias, and R. Kitamura, "Impact of telecommuting on spatial and temporal patterns of household travel," Transportation, vol. 18, pp. 383-409, 1991.

[22] S. Gössling, "ICT and transport behavior: a conceptual review," International Journal of Sustainable Transportation, vol. 12, no. 3, pp. 153-164, 2018.

[23] R. Hamer, E. Kroes, and H. Van Ooststroom, “Teleworking in the Netherlands: an evaluation of changes in travel behaviour," Transportation, vol. 18, no. 4, pp. 365-382, 1991.

[24] P. L. Mokhtarian, "A conceptual analysis of the transportation impacts of $\mathrm{B} 2 \mathrm{C}$ e-commerce," Transportation, vol. 31, no. 3, pp. 257-284, 2004.

[25] B. E. Tonn and A. Hemrick, "Impacts of the use of e-mail and the internet on personal trip-making behavior," Social Science Computer Review, vol. 22, no. 2, pp. 270-280, 2004.

[26] A. Aguiléra, C. Guillot, and A. Rallet, "Mobile ICTs and physical mobility: review and research agenda," Transportation Research Part A: Policy and Practice, vol. 46, no. 4, pp. 664-672, 2012.

[27] P. N. Balepur, K. V. Varma, and P. L. Mokhtarian, “Transportation impacts of center-based telecommuting: interim findings from the neighborhood telecenters project," Transportation, vol. 25, no. 3, pp. 287-306, 1998.

[28] K. Shi, J. De Vos, Y. Yang, and F. Witlox, "Does e-shopping replace shopping trips? empirical evidence from Chengdu,
China," Transportation Research Part A: Policy and Practice, vol. 122, pp. 21-33, 2019.

[29] G. Xi, F. Zhen, X. Cao, and F. Xu, "The interaction between e-shopping and store shopping: empirical evidence from Nanjing, China," Transportation Letters, vol. 12, pp. 1-9, 2018.

[30] A. Andersson, L. Winslott Hiselius, and E. Adell, "Promoting sustainable travel behaviour through the use of smartphone applications: a review and development of a conceptual model," Travel Behaviour and Society, vol. 11, pp. 52-61, 2018.

[31] M. Kroesen and S. L. Handy, "Is the rise of the e-society responsible for the decline in car use by young adults? results from the Netherlands," Transportation Research Record: Journal of the Transportation Research Board, vol. 2496, no. 1, pp. 28-35, 2015.

[32] V. Varghese and A. Jana, "Impact of ICT on multitasking during travel and the value of travel time savings: empirical evidences from Mumbai, India," Travel Behaviour and Society, vol. 12, pp. 11-22, 2018.

[33] J. Tang, F. Zhen, J. Cao, and P. L. Mokhtarian, "How do passengers use travel time? a case study of Shanghai-Nanjing high speed rail," Transportation, vol. 45, no. 2, pp. 451-477, 2018.

[34] E. Ben-Elia, G. Lyons, and P. L. Mokhtarian, "Epilogue: the new frontiers of behavioral research on the interrelationships between ICT, activities, time use and mobility," Transportation, vol. 45, no. 2, pp. 479-497, 2018.

[35] Y. Qiao, X. Zhao, J. Yang, and J. Liu, "Mobile big-data-driven rating framework: measuring the relationship between human mobility and app usage behavior," IEEE Network, vol. 30, no. 3, pp. 14-21, 2016.

[36] B. Van Wee, K. Geurs, and C. Chorus, "Information, communication, travel behavior and accessibility," Journal of Transport and Land Use, vol. 6, no. 3, pp. 1-16, 2013.

[37] V. Varghese and A. Jana, "Interrelationships between ICT, social disadvantage, and activity participation behaviour: a case of Mumbai, India," Transportation Research Part A: Policy and Practice, vol. 125, pp. 248-267, 2019.

[38] Y. Yim, A. J. Khattak, and J. Raw, "Traveler response to new dynamic information sources: analyzing corridor and area wide behavioral surveys," Transportation Research Record: Journal of the Transportation Research Board, vol. 1803, no. 1, pp. 66-75, 2002.

[39] K. K. Srinivasan and P. N. Raghavender, "Impact of mobile phones on travel: empirical analysis of activity chaining, ridesharing, and virtual shopping," Transportation Research Record: Journal of the Transportation Research Board, vol. 1977, no. 1, pp. 258-267, 2006.

[40] C. G. Chorus, T. A. Arentze, H. J. P. Timmermans, E. J. E. Molin, and B. Van Wee, "Travelers' need for information in traffic and transit: results from a web survey," Journal of Intelligent Transportation Systems, vol. 11, no. 2, pp. 57-67, 2007.

[41] R. N. Buliung, K. Soltys, R. Bui, C. Habel, and R. Lanyon, "Catching a ride on the information super-highway: toward an understanding of internet-based carpool formation and use," Transportation, vol. 37, no. 6, pp. 849-873, 2010.

[42] A. J. Khattak, X. Pan, B. Williams, N. Rouphail, and Y. Fan, "Traveler information delivery mechanisms: impact on consumer behavior," Transportation Research Record: Journal of the Transportation Research Board, vol. 2069, no. 1, pp. 77-84, 2008.

[43] Y.-Y. Tseng, J. Knockaert, and E. T. Verhoef, “A revealedpreference study of behavioural impacts of real-time traffic 
information," Transportation Research Part C: Emerging Technologies, vol. 30, pp. 196-209, 2013.

[44] Z. Xiang, D. Wang, J. T. O'Leary, and D. R. Fesenmaier, "Adapting to the internet: trends in travelers' use of the web for trip planning," Journal of Travel Research, vol. 54, no. 4, pp. 511-527, 2015.

[45] A. Delbosc and G. Currie, "Changing demographics and young adult driver license decline in Melbourne, Australia (1994-2009)," Transportation, vol. 41, no. 3, pp. 529-542, 2014.

[46] C. R. Bhat and R. Sardesai, "The impact of stop-making and travel time reliability on commute mode choice," Transportation Research Part B: Methodological, vol. 40, no. 9, pp. 709-730, 2006.

[47] E. Fishman, S. Washington, and N. Haworth, "Bike share's impact on car use: evidence from the United States, Great Britain, and Australia," Transportation Research Part D: Transport and Environment, vol. 31, pp. 13-20, 2014.

[48] V. Helminen and M. Ristimäki, "Relationships between commuting distance, frequency and telework in Finland," Journal of Transport Geography, vol. 15, no. 5, pp. 331-342, 2007.

[49] J. Zhu and Y. Fan, "Commute happiness in Xi'an, China: effects of commute mode, duration, and frequency," Travel Behaviour and Society, vol. 11, pp. 43-51, 2018.

[50] J. Benesty, J. Chen, Y. Huang, and I. Cohen, "Pearson correlation coefficient," in Noise Reduction in Speech Processing, pp. 1-4, Springer, Berlin, Germany, 2009.

[51] N. S. Daisy, M. H. Hafezi, L. Liu, and H. Millward, "Understanding and modeling the activity-travel behavior of university commuters at a large Canadian university," Journal of Urban Planning and Development, vol. 144, Article ID 04018006, 2018.

[52] J. P. Carini, On Modeling the Generation and Organization of Household Activity Stops, University of Texas at Austin, Austin, TX, USA, 1998.

[53] X. Wang, C. Shao, C. Yin, and C. Dong, "Exploring the effects of the built environment on commuting mode choice in neighborhoods near public transit stations: evidence from China," Transportation Planning and Technology, vol. 44, no. 1, pp. 111-127, 2021. 